\title{
Flipped Versus Traditional: An Analysis of Teaching Techniques in Finance and Psychology
}

\section{ABSTRACT}

Recently there has been a surge of interest in technology-aided teaching strategies such as the flipped classroom. Given the growing interest in these techniques, it is important to critically evaluate their effectiveness and to begin to examine factors that might shape how effective the flipped classroom will be in a given educational setting. Although most existing research on the flipped classroom suggests an advantage of the flipped approach over a more traditional lecture approach, most of this research has been conducted in a single educational setting at a time and in ways that preclude definitive conclusions about the relative effectiveness of the flipped approach. We present the results of a study that addressed many of these methodological limitations and compared the effectiveness of the flipped approach to a traditional lecture approach across two semesters in courses from two different disciplines, finance and psychology. We found that the effectiveness of the flipped versus the traditional approach varied across the two courses. In particular, in the psychology courses the flipped approach resulted in superior performance on quizzes administered immediately after exposure to course material, but resulted in similar performance on exams administered some time after initial exposure. In contrast, in the finance courses the flipped approach resulted in similar performance on immediately administered quizzes, but superior performance on lateradministered exams. These results contribute to the burgeoning literature on the flipped classroom both by addressing methodological limitations found in previous work and by identifying some of the specific conditions under which the flipped approach may be a good pedagogical choice.

\section{KEYWORDS}

confounding variables, finance, flipped classroom, psychology, video lecture

\section{INTRODUCTION}

According to Bishop and Verleger (2013) the flipped classroom is a pedagogical method that uses video lectures and practice problems as homework, and active, group-based problem-solving activities in the classroom. This approach is often contrasted with the traditional lecture approach, in which classroom time is used primarily for the delivery of lecture material to students, with additional class time sometimes used to engage students in basic comprehension activities, typically with scarce active learning exercises and practice problems. Although flipping the classroom has grown in popularity over recent years, given that implementing the flipped approach often involves the investment of significant time and energy on the part of instructors (e.g., recording video lectures; designing additional in-class activities), it is important to gain a good understanding of whether the flipped approach really is 
more effective than traditional approaches and of the factors that may affect when and where the flipped approach is a good pedagogical choice.

Scholars have recognized the need for research on this issue, and the past few years have seen a wealth of scholarship examining the relative effectiveness of the flipped approach. In general, this work has supported the idea that the flipped approach may be more effective than the traditional approach, in terms of both student perceptions (e.g., Fisher, Ross, LaFerriere, \& Maritz, 2017; Harjoto, 2016; Kim, Kim, Khera, \& Getman, 2014; Strayer, 2007; Zappe, Leicht, Messner, Litzinger, \& Lee, 2009), and student performance (e.g., course grades: Day \& Foley, 2006; Findlay-Thompson \& Mombourquette, 2014; Moravec, Williams, Aguilar-Roca, \& O’Dowd, 2010; Ruddick, 2012). Critically, however, although the bulk of existing research on the flipped classroom approach is consistent with the idea that the flipped approach enjoys an advantage over the traditional approach, because of the ways in which most existing studies have been designed it is difficult to draw confident causal conclusions regarding the pedagogical effectiveness of the flipped classroom. This is because most existing study designs contain confounding variables, which are factors that vary along with the proposed causal factor (in this case, flipped versus traditional approach). Confounds are problematic because any time groups differ in more than one way, we cannot be sure which of those differences is the cause of the groups' later performance.

Although we return to this point later, consider the example of a typical study design that assigns one section of a course to be taught using the flipped approach, a second section of the course to be taught using a more traditional lecture approach, and then compares student test scores from the two sections. Because the two sections differ in myriad ways other than the approach they were exposed to (e.g., they are composed of different students, they take place at different times of day), we cannot be sure which of these factors is the cause of any difference in performance that we observe between the sections.

One way in which the present study adds value to the existing literature on the flipped classroom is by controlling for common confounding variables, a task that to the best of our knowledge has not yet been undertaken in studies of the relative effectiveness of the flipped approach. Additionally, by analyzing the effectiveness of the flipped teaching technique simultaneously in two different disciplines our work also adds value in a second way, by examining whether the effectiveness of the flipped approach varies across disciplines. To our knowledge, this is the first study that analyzes quantitative and qualitative data on flipped classrooms for more than one discipline at a time. As outlined above, gaining a more thorough understanding of when and where the flipped approach might represent a good pedagogical choice is an important task for scholars because it can help educators make better-informed decisions about the likely effectiveness of the flipped approach within their particular educational setting.

\section{LITERATURE REVIEW}

As noted above, recent years have seen an explosion of scholarly interest in the flipped classroom. The majority of existing work suggests that the flipped approach is associated both with more positive student perceptions than traditional lecture approaches and, of central relevance to the present work, superior course performance (e.g., course grades). With respect to student perceptions, research has consistently demonstrated that students report positive perceptions of the flipped classroom technique (e.g. Fisher et al. 2017; Harjoto, 2016; Kim et al., 2014; Strayer, 2007; Zappe et al., 2009) 
though, notably, these positive perceptions sometimes emerge only after students overcome initial frustration and lack of familiarity with the flipped approach (e.g., Fisher et al., 2017; Strayer, 2007).

Of course, positive student perceptions are not always accompanied by improved student performance. As such, a variety of studies have examined the impact of the flipped approach on various metrics of student performance (e.g., exam grades; overall course grades), focusing either on performance alone or in combination with perceptions. For instance, Day and Foley (2006) studied the effectiveness of the flipped classroom in a senior-level human-computer interaction course. They taught concurrent sections of the course, one using a flipped approach and a second using a traditional approach and found that students in the flipped classroom scored higher on homework, projects, and tests thus earning higher overall course grades. Findlay-Thompson and Mombourquette (2014) studied the flipped classroom in an introductory business class, and found that students earned higher quiz grades when they were taught in a flipped manner instead of a traditional lecture method (though test performance did not differ). Moravec et al. (2010) flipped selected topics in an introductory biology class and found that students earned 21 percent higher grades on exam questions related to those topics than did previous cohorts who experienced the topics in a traditional lecture format. Lastly, Ruddick (2012) flipped a college preparatory chemistry course and found that students in the flipped class scored higher on their final exams, became more interested and less intimidated by chemistry, and found the online videos and PowerPoints useful. Taken together then, this work has generally supported the idea that, across a wide variety of disciplines and course levels (e.g., introductory versus advanced courses), the flipped classroom is associated with superior student performance

In addition to the above flipped classroom studies, there is a strand of work that analyzes the effectiveness of out-of-class videos as a complement instead of a substitute for in-class lectures. These studies include Drouin (2014); Ford, Burns, Mitch, and Gomez (2012); He, Swenson, and Lents (2012); Kay and Kletskin (2012); and Lloyd and Robertson (2012), among others.

Both Drouin (2014) and Lloyd and Robertson (2012), studied the effectiveness of class videos when used as a complement to in-class lectures. They compared sections of a course in which supplemental videos were made available to students in concurrently taught sections of the same course that did not include supplemental videos. In her analysis of two sections of introductory psychology, Drouin found that many students in the treatment section (with access to supplemental lecture videos) used these as a substitute rather than a complement for their face-to-face lecture, attended class less frequently, and earned lower final grades than did the students in the control section of the course. On the other hand, Lloyd and Robertson, in their analysis of the impact of screencast tutorials on statistical knowledge, application, and interpretation, found that students who were randomly assigned a video instead of a text tutorial to help them solve statistics problems earned higher grades in their upper-level statistics course.

Ford et al. (2012) and He et al. (2012) also provided students with supplemental videos and analyzed the effectiveness of these in their courses, although they do so by comparing student performance in courses with supplemental videos to courses taught previously and not concurrently to the treatment course. Ford et al. studied the potential benefits of audio and video lecture recording as a supplement to a lecture in two general psychology courses. They found no difference in course grades in the semesters when audio and video lecture recording was or was not used. He et al., on the other hand, used supplemental video tutorials only on challenging concepts and problems in an undergraduate 
analytical chemistry course. They found videos to be an effective tool in helping students improve their chemistry problem solving skills. Finally, Kay and Kletskin (2012) used video podcasts to strengthen students' pre-calculus skills in the first three weeks of a freshman undergraduate calculus course. Student surveys as well as pre- and post-test scores showed the podcasts were effective in helping students learn pre-calculus concepts.

Although the work on videos as complement to in-class lecture paints a more mixed picture than work focusing more specifically on out-of-class videos as a substitute for in-class lectures, overall the bulk of this work reiterates the positive impact the flipped classroom has had in the classroom. However, as noted above it can be challenging to draw confident conclusions from most studies on the flipped classroom given the presence of confounding variables. We turn now to a fuller discussion of this issue along with an explanation of how the present study seeks to control for common confounding variables found in existing research on the relative effectiveness of the flipped classroom.

\section{COMMON DESIGNS OF STUDIES ON EFFECTIVENESS OF THE FLIPPED CLASSROOM}

Consider the first common study design in the literature on the flipped classroom. In this design, an instructor typically takes two different sections of the same course and teaches students in one section using the traditional approach and students in the second section using the flipped approach (e.g., Day \& Foley, 2006; Findlay-Thompson \& Mombourquette, 2014; Moravec et al., 2010; Strayer, 2007). In this design, there are numerous factors other than the teaching approach students are exposed to that could differentiate the two sections of the course. For example, the two sections of the course are also composed of different groups of students, groups that vary on a number of factors likely to affect their performance (e.g., preexisting intellectual ability, past exposure to relevant information or problemsolving approaches, group chemistry and cohesion). Additionally, the two sections of the course differ in a variety of environmental variables (e.g., time of day of the course, classroom in which the course is taught) that could also plausibly affect student or instructor performance. The presence of these confounding variables makes it impossible to know for certain whether any differences in performance observed between the two sections are due to teaching method (the flipped versus traditional approach, the proposed causal variable) or to these other differences between the sections that could plausibly affect student performance.

The second common design in research on the flipped classroom-focusing on only a single section of the course and teaching some topics in the course using a flipped methodology and other topics in the course using a traditional methodology_largely eliminates confounds associated with teaching one section of a course using the flipped approach and a different section of the course using the traditional approach. Although this approach has the advantage of ruling out differences between students, time of day, and the like as possible explanations for any differences in performance observed between the flipped and traditional topics, it suffers from a different set of problems. For example, this approach ensures that the flipped topics will necessarily be different from the traditional topics. The problem here is that we cannot be sure whether any differences we observe between the flipped and traditional topics are due to the manner of presentation (i.e., flipped versus traditional) or to differences in the difficulty of the flipped versus traditional topics themselves.

In our study, we attempted to address both of these methodological issues to provide a more definitive test of the causal efficacy of the flipped versus traditional approach. To eliminate differences in 
class composition, differences in time of day, differences in classroom, and the like as confounding factors, we focused on single sections of courses, teaching some topics in flipped format and others in traditional format. Additionally, to eliminate differences in difficulty of the flipped versus traditional topics as a confounding factor, we conducted the study over two consecutive semesters and varied the topics that were taught in traditional versus flipped format each semester. Because each of our focal topics were thus taught in flipped versus traditional format the same total number of times, differences in difficulty of the material itself can be ruled out as a plausible cause of any differences we observed between the flipped and traditional sections of the course. We illustrate the design below in table 1 .

Table 1. Topics as a function of semester, instruction type (flipped versus traditional) and course (finance versus psychology)

\begin{tabular}{|c|c|c|c|}
\hline INSTRUCTION TYPE & DISCIPLINE & \multicolumn{2}{|l|}{ SEMESTER/ COURSES } \\
\hline & & Semester 1 & Semester 2 \\
\hline \multicolumn{4}{|l|}{ Traditional } \\
\hline & finance & $\begin{array}{l}\text { International Financial Markets; } \\
\text { Country Risk }\end{array}$ & $\begin{array}{l}\text { International Flow of Funds; } \\
\text { Government Intervention }\end{array}$ \\
\hline & psychology & History of Psychology; Learning & $\begin{array}{l}\text { Research Methods; } \\
\text { Psychological Disorders }\end{array}$ \\
\hline \multicolumn{4}{|l|}{ Flipped } \\
\hline & finance & $\begin{array}{l}\text { International Flow of Funds; } \\
\text { Government Intervention }\end{array}$ & $\begin{array}{l}\text { International Financial Markets; } \\
\text { Country Risk }\end{array}$ \\
\hline & psychology & $\begin{array}{l}\text { Research Methods; Psychological } \\
\text { Disorders }\end{array}$ & History of Psychology; Learning \\
\hline
\end{tabular}

\section{METHOD}

\section{Participants}

This study took place at a Jesuit liberal arts university in the Northeast region of the United States. A total of 143 students took part in the study over the course of the spring 2016 and fall 2016 semesters. Of these, 94 ( 15 female and 33 male in spring 2016; 11 female and 35 male in fall 2016) were enrolled in an international finance course and 49 ( 17 female and 5 male in spring 2016; 22 female and 4 male in fall 2016) were enrolled in an introductory course in psychology. The international finance course is an upper-level finance course. Students enrolled in this course are primarily majoring or minoring in finance and have a junior or senior standing. The general psychology course is an introductory survey course in psychology. Students enrolled in this course are primarily majoring or minoring in psychology, although a number of non-majors or minors also take the course to fulfill core curriculum requirements. The majority of students have freshman or sophomore standing. Both courses meet twice a week for 75 minutes each time.

\section{Procedure}

In each semester, two topics from each course were taught in a traditional format and two in flipped format (we refer to these as the focal topics). The topics that were taught in traditional format the first semester were taught in flipped format the second semester and vice versa. As discussed above, this helps to ensure that any differences observed between student performance on the traditional and 
flipped topics is not simply a result of differences in difficulty between the topics themselves. For the first semester of the finance course, the topics of international financial markets and country risk were taught in traditional format and the topics on international flow of funds and government intervention were taught in flipped format; the pairings were reversed in the second semester. For the first semester of the psychology course, the topics of the history of psychology and learning were taught in traditional format, and the topics of research methods and psychological disorders in flipped format; the pairings were reversed in the second semester.

For the flipped presentation, students were asked to watch a video lecture on the topic prior to class. After answering any student questions about the material covered in the video lecture, the instructors then spent the rest of the class period engaging students in an activity designed to give them practice in applying what they had learned in the video lecture. In the finance flipped classroom, in-class sessions focused on discussing and analyzing news articles or problems that showed a real-life application of the topic presented in the video lecture. The analysis of these articles involved using the tools the students learned about in the video they watched at home. The psychology flipped classroom in-class sessions included activities that asked students to interpret novel instructor-provided examples in light of concepts covered in the video lecture or to come up with their own novel examples to illustrate those concepts. In both courses, students learned about the basic theories at home through the video, while in class the focus was on applying the material they learned. The in-class sessions then provided a first opportunity for students to practice analyzing and applying many of these concepts covered in the videos.

For the traditional presentation, students were asked to read the sections of the textbook relevant to the topic prior to coming to class, and the instructor then spent the class period delivering a lecture on the topic. Critically, we made sure to assign students an out-of-class activity for both the flipped and traditional presentations to ensure that they had relatively similar amounts of exposure to the material in both the flipped and traditional conditions. This helped to eliminate the possibility that any advantage of the flipped approach is due to students' simply receiving greater exposure to the material (i.e., time spent out of class watching the videos plus class time spent doing the activity for flipped versus just class time spent engaging with the lecture for traditional), and not to any particular unique advantage of the flipped approach, such as its use of class time for hands-on activities. Of course, if the advantage of the flipped approach is simply the result of greater exposure to the material, instructors could achieve the same results by, for example, assigning students more homework or enacting policies to ensure that they review material, rather than going through the additional trouble of recording video lectures and designing in-class activities.

For all of the focal topics, we gathered two different indicators of student performance. First, immediately upon completion of each of the focal topics, students completed a short in-class quiz on the material. In both the international finance and general psychology courses, each quiz consisted of 10-12 questions. Quizzes included both factual and critical-thinking questions. Students were given 10 minutes at the end of each class to take the quiz. In total, students took four quizzes during the semester (each representing one of the four topics in this study), and these represented between 5 percent and 6 percent of their overall grade in both courses.

Second, students were tested again later in the semester via cumulative exams that included material on the focal topics along with material from additional course topics. This allowed us to see 
how the traditional versus flipped format affected student performance on different types of assessments at different time delays - namely, student performance on quizzes testing only the focal material and administered immediately after exposure to the material and student performance on exams testing the focal material along with other material and administered some time after initial exposure to the material. For both courses the weight of each topic (included in this study) on tests was between 16 percent and 18 percent of the total points on the test. Note that when we reference exam performance in our analyses, we are speaking specifically about student performance on those sections of the exam that were taught in flipped format one semester and traditional format another semester, not the overall exam performance. That is, a grade of 100 percent means students got all questions regarding topics considered in this study correct, but it does not say anything about whether answers to other course topics included in an exam but not in this study were correct or incorrect.

It should also be noted that the length of time between exposure to the material and assessment was similar in both the flipped and traditional conditions. In both conditions, quizzes were administered immediately upon completion of the class meeting devoted to the particular topic (although the way in which class time was spent was of course different in the flipped and traditional conditions). And exams always occurred a set number of classes after completion of each topic, regardless of whether the topic had been taught in a flipped or traditional format. Keeping the time between exposure to material and assessment (relatively) constant between the flipped and traditional conditions is important because it helps to ensure that any differences in student performance between the conditions are not due simply to longer delays between exposure and assessment in one condition versus the other.

Finally, at the end of the semester students also completed an anonymous survey about their experience with the course, with particular emphasis on their reactions to the flipped sections of the course (the full survey is reproduced in the Appendix).

\section{RESULTS}

Descriptive statistics can be seen in table 2 . To analyze the data, we conducted a mixed $2 \times 2 \times 2$ ANOVA, with course (finance versus psychology) as a between subjects variable and delivery type (traditional versus flipped) and assessment type (quiz versus exam) as within subjects variables. ${ }^{1}$

Table 2. Student performance as a function of course (finance versus psychology), instruction type (flipped versus traditional), and assessment type (quiz versus exam)

\begin{tabular}{|l|l|l|l|l|}
\hline COURSE & INSTRUCTION TYPE & PERFORMANCE & OVERALL \\
\hline & & QUIZ & EXAM & \\
\hline Finance & & & & $81.77(10.37)$ \\
\hline & traditional & $86.60(13.19)$ & $76.93(14.96)$ & $82.46(9.80)$ \\
\hline & flipped & $84.43(10.42)$ & $80.50(13.68)$ & \\
\hline Psychology & & & & $81.98(13.92)$ \\
\hline & traditional & $82.26(12.77)$ & $81.71(18.00)$ & \\
\hline $\begin{array}{l}\text { Finance and } \\
\text { psychology, } \\
\text { combined }\end{array}$ & flipped & $86.86(11.71)$ & $82.93(13.16)$ & \\
\hline
\end{tabular}


This analysis revealed a significant effect of assessment type, $F(1,118)=18.22, p<.001$, partial $\eta^{2}=.13$, such that students performed significantly better on quizzes $(M=85.04)$ than on exams $(M=80.51)$. This effect was qualified by a significant two-way interaction between assessment type and course, $F(1,118)=4.61, p=.03$, partial $\eta^{2}=.04$. The nature of this interaction was such that in the finance classes, students performed significantly better on quizzes $(M=85.51, S D=9.23)$ than on exams $\left(M=78.71, S D=11.03 ; F(1,77)=22.69, p<.001\right.$, partial $\left.\eta^{2}=.23\right)$ whereas in the psychology classes, students performed better on quizzes $(M=84.56, S D=10.43)$ than exams $(M=82.31, S D=12.03)$ although this difference did not reach a traditionally accepted level of significance, $F(1,41)=3.90, p<.06$, partial $\eta^{2}=.09 .^{2}$

Most central to the present analysis, a significant three-way interaction also emerged among course, instruction type, and assessment type, $F(1,118)=4.12, p<.05$, partial $\eta^{2}=.03$. As can be seen in tables 3 and 4, the nature of this interaction was such that in the finance class, students' quiz grades did not differ in the flipped $(M=84.43, S D=10.42)$ and the traditional $(M=86.60, S D=13.19)$ sections of the course, $F(1,77)=1.64, p=.20$, partial $\eta^{2}=.02$, but students' exam scores were significantly higher in the flipped $(M=79.65, S D=13.14)$ than the traditional $(M=75.75, S D=14.54)$ sections of the course, $F(1,93)=4.89, p<.03$, partial $\eta^{2}=.05$. In contrast, in the psychology classes, students' quiz grades were higher in the flipped $(M=87.21, S D=11.52)$ than the traditional $(M=82.00, S D=13.15)$ sections of the course. $F(1,44)=7.04, p=.01$, partial $\eta^{2}=.14$, but students' exam scores did not differ in the flipped $(M=83.45, S D=13.13)$ and traditional $(M=82.08, S D=17.70)$ sections, $F(1,43)=.21, p=.65$, partial $\eta^{2}<.01$. Thus, the advantage of the flipped classroom was limited to test scores in the finance class, but to quiz scores in the psychology class. No other significant main effects or interactions emerged.

Table 3. Quiz performance as a function of course (finance versus psychology) and instruction type (flipped versus traditional)

\begin{tabular}{|l|l|l|l|l|}
\hline COURSE & INSTRUCTION TYPE & $M$ & SD & F-test \\
\hline Finance & & & & \\
\hline & traditional & 86.60 & 13.19 & $F(1,77)=1.64, p=.20$ \\
\hline & flipped & 84.43 & 10.42 & \\
\hline Psychology & & & & \\
\hline & traditional & 82.00 & 13.15 & $F(1,44)=7.04, p=.02$ \\
\hline & flipped & 87.21 & 11.52 & \\
\hline
\end{tabular}

Table 4. Test performance as a function of course (finance versus psychology) and instruction type (flipped versus traditional)

\begin{tabular}{|l|l|l|l|l|}
\hline COURSE & INSTRUCTION TYPE & $M$ & $S D$ & $F$-test \\
\hline Finance & & & & \\
\hline & traditional & 75.75 & 14.54 & $F(1,93)=4.89, p=.03$ \\
\hline & flipped & 79.65 & 13.14 & \\
\hline Psychology & & & & \\
\hline & traditional & 82.08 & 17.70 & $F(1,43)=.21, p=.65$ \\
\hline & flipped & 83.45 & 13.13 & \\
\hline
\end{tabular}


Recall that we also surveyed students on their perceptions of any advantages of the flipped classroom approach. Student survey results showed that more than three quarters of both psychology and finance students agreed the videos lectures helped them understand the course material and roughly two-thirds of the students in each course agreed they liked watching the videos. Almost 90 percent of the students in each course also agreed that the in class activities they did after watching the videos helped them to understand the course material. Overall, student comments on the flipped classroom emphasized that they liked videos because they could watch them at their own pace, go back and review them, come to class prepared, and focus on the aspects of the topic that were not clear, as well as get hands-on experience with activities and problems.

However, about half of the students in each course felt they learned more from traditional lectures than they did from the class time spent on activities. In addition, only about 30 percent of psychology students and 46 percent of finance students felt they understood the flipped material better than the traditional material. Only 34 percent of psychology students and 45 percent of finance students felt they were more engaged with the flipped material than they were with the traditional material. Student comments on the traditional lecture classes emphasized that they like class lectures because they find them motivating and engaging. They liked being able to ask questions as they arise and to hear other students' questions.

Although students derived a benefit from the flipped classroom, the above survey results show that students found both flipped classroom and lecture valuable strategies for their learning. In sum, the survey data showed students like the flipped classroom approach and found that it helped them learn. However, the flipped approach did not seem superior to the lecture in terms of their learning or understanding of class material or their level of engagement.

\section{DISCUSSION}

As technology-assisted teaching tools and strategies become more numerous and more widely available, instructors are faced with sometimes difficult decisions about whether or not to implement these tools in their own classrooms. Changing a course to incorporate emerging technologies can have a sizable impact on student outcomes, and designing new course components takes time and resources, both of which are limited. As such, it is critical that instructors' decisions regarding the adoption of new technologies or teaching approaches is based on good information about the educational effectiveness of these tools and strategies. In this study we sought to provide such information about the flipped classroom, one popular technology-assisted teaching approach. We went beyond existing research on the flipped classroom in two key ways, analyzing the impact of the flipped technique on student performance in two different disciplines, finance and psychology, and also correcting for some common methodological issues in existing studies of the flipped classroom to allow for a more valid test of its pedagogical effectiveness.

Overall, we found that the effectiveness of the flipped classroom approach varied across the two disciplines. Specifically, students in a flipped classroom in the psychology courses-but not those in the finance courses - performed better than did those in a traditional classroom on quizzes administered immediately after presentation of the material. But students in a flipped classroom in the finance courses - but not those in the psychology courses - performed significantly better than did students in traditional classrooms on exams administered some time after initial exposure to the material. 
Why did we see that the flipped approach was effective only on immediately administered quizzes in the psychology courses, but on later-administered exams in the finance courses? Although this particular project cannot give us definitive reasons for this difference, we offer a few possibilities here, possibilities that could be examined in future research. First, it could be the case that, for whatever reason $(\mathrm{s})$, students in the psychology and finance courses watched the videos at different times. For example, if students in the psychology courses primarily watched the videos immediately prior to the quizzes but then failed to go back and review the videos prior to the exams, it could be the case that they initially benefited from greater exposure to the material on the quizzes but the effect of this greater exposure faded by the time they arrived at the exams. If students in the finance courses instead primarily used the videos as a way to review prior to the exams, rather than as a way to prepare for the quizzes, the benefit of the videos would have emerged only on the exams. Although we asked students in the end-ofsemester survey if they watched the videos, we did not gather data about when they watched the videos or about how often they watched the videos. Data such as this could be helpful in pinpointing why we observed differential effectiveness of the flipped approach on the tests versus quizzes in the two classes.

Of course, these results could also be due to differences in how a flipped approach fits with the different types of content and course goals found in the very different courses examined here. The introductory-level psychology course, for example, is focused primarily on helping students to build a knowledge of the general foundational concepts of the field. It is focused mainly on mastery of content. A flipped approach may help students to grasp and master the material in such a content-focused course more quickly as it can provide them with hands-on opportunities to apply what they have learned in the out-of-class lectures immediately after they are exposed to the content of those lectures. Students will eventually come to grasp this content in a traditional classroom environment as well, but this will take time as content is reviewed and connected with other course material. Thus, in more introductory content-based courses like the introductory psychology course the advantage of a flipped approach that asks students to watch lectures outside of class and then uses class time to engage them in hands-on application of lecture content may emerge early, but students in the traditional classroom can catch up over time.

The more advanced finance course, in contrast, is focused primarily on helping students to apply basic knowledge to novel examples and problems. In such a course, the flipped classroom is unlikely to enable students to immediately apply what they have learned on their own to novel problems, and so it is unlikely to lead to better performance on assessments administered immediately after exposure to the flipped material. But it is likely to give them a head start in doing such application effectively by introducing them to the basic concepts sooner and scaffolding them through practice with guided applications. Thus, in more advanced application-based courses such as the finance course, the benefits of the flipped approach may accrue over time as the earlier exposure to basic concepts and additional practice with guided applications provided by the flipped approach enables students to spend more time on application of those concepts by the time the exam rolls around. Of course, this is only one possible explanation for the differences in effectiveness of the flipped versus traditional approaches on the different assessments in the two courses. The larger point here is that these results highlight the need for greater consideration of the ways in which the flipped approach might fit with different types of courses and different types of learning goals. 
To this point, we have focused mainly on how the effectiveness of a flipped approach may differ as a function of aspects of the specific course(s) in which it is employed. Although course characteristics are no doubt important here, it is also important to remember that both flipped approaches and traditional approaches themselves can differ and so the specific ways in which flipped versus traditional class sessions are conceived and conducted will have an impact on their relative effectiveness. In our study, for example, we were very careful to make sure that flipped sections of the course always used class time for hands-on activities aimed at helping students to apply content and that traditional sections of the course always used class time to present lecture material, largely in the absence of hands-on application activities. But, of course, instructors could use class time for such hands-on application activities without also asking students to first watch content lectures outside of class. Rather than asking simply whether a flipped or traditional approach is better, instructors may be better served by identifying the specific techniques and activities most likely to lead to student success in their course, and then considering whether these techniques and activities can be more easily instantiated using a flipped or traditional approach.

It is also important to note here that although the flipped approach did not result in better performance across the board in either course, it resulted in performance that was at least as good as that observed in the traditional classroom on both quizzes and exams in both courses. As such, these results suggest that the flipped classroom approach may be a fruitful strategy for instructors to pursue. At best, it shows promise to increase student performance, and, at worst, it results in performance that is at least on par with that observed in the traditional classroom. It is also worth noting an additional advantage of the flipped approach, one not reflected in quiz and test performance: students in both courses reported very positive perceptions of the flipped approach, which suggests that its benefits extend beyond mere improvement of test scores.

Of course, there is also room for improvement in this study. The ability to analyze a greater number of classes or students as well as flipping more topics in a course could provide additional insight into the effectiveness of the flipped classroom technique, and allow for greater understanding of factors that might moderate the effectiveness of the flipped approach. For example, perhaps non-native speakers benefit more from access to out-of-class videos than do native speakers. For non-native speakers, out-ofclass videos may provide an opportunity to watch (and re-watch) course material at their own pace, which may result in significantly greater understanding than exposure to a single lecture, during which they may have difficulty understanding all of the material. Because native speakers are likely to have less difficulty understanding lecture material, access to videos may not have as much of an impact on them. Because the student population in this study was composed overwhelmingly of native English speakers (over 97 percent of the student population at the university where this study was conducted is native English speaking), it does not permit for an examination of this issue. Additional research is needed to examine this and other potential moderating factors (e.g., different disciplines, introductory-level versus higher-level courses). These limitations notwithstanding, however, the present study demonstrated that the flipped approach was effective to some degree in both courses, and the results suggest a number of interesting directions for future research. 
Michael Andreychik is an Associate Professor of Psychology at Fairfield University (USA). He is a social psychologist studying attitudes and emotions and works with colleagues at the intersection of research and pedagogy as a faculty liaison in Fairfield's Center for Academic Excellence.

Valeria Martinez is an Associate Professor of Finance at Fairfield University (USA). Her research focuses on empirical finance and pedagogy; her goal in the classroom is for students to become inspired and learn.

\section{NOTES}

1. We conducted a second set of analyses including gender as an additional between-subjects factor. Gender did not moderate any of the effects reported here so for simplicity's sake we report the analyses including our primary variables of interest: course, delivery type, and assessment type.

2. Degrees of freedom differ across analyses and from the total sample size due to missing data. Not all students completed all of the quizzes or tests.

\section{REFERENCES}

Bishop, J. L., \& Verleger, M. A. (2013, June). The flipped classroom: A survey of research. Paper presented at the 2013 Annual Conference \& Exposition of the American Society for Engineering Education, Atlanta, Georgia. Retrieved from https://peer.asee.org/22585

Day, J. A., \& Foley, J. D. (2006). Evaluating a web lecture intervention in a human-computer interaction course. IEEE Transactions on Education, 49(4), 420-431. Retrieved from https://ieeexplore.ieee.org/document/4012664

Drouin, M. A. (2014). If you record it, some won't come: Using lecture capture in introductory psychology. Teaching of Psychology, 41(1), 11-19. https://doi.org/10.1177/0098628313514172

Findlay-Thompson, S., \& Mombourquette P. (2014). Evaluation of a flipped classroom in an undergraduate business course. Business Education \& Accreditation, 6(1), 63-71. Retrieved from https://ssrn.com/abstract $=2331035$

Fisher, R., Ross, B., LaFerriere, R. \& Maritz, A. (2017). Flipped, learning, flipped satisfaction, getting the balance right. Teaching \& Learning Inquiry, 5(2), 114-127. https://doi.org/10.20343/teachlearninqu.5.2.9

Ford, M. B., Burns, C. E., Mitch, N., \& Gomez, M. M. (2012). The effectiveness of classroom capture technology. Active Learning in Higher Education, 13(3), 191-201. https://doi.org/10.1177/1469787412452982

Harjoto, M. A. (2016). MBA students perceptions on pre-lecture videos for corporate finance core course. Journal of Financial Education, 42 (1/2), 81-101. http://www.jstor.org/stable/90000837

He, Y., Swenson, S., \& Lents, N. (2012). Online video tutorials increase learning of difficult concepts in an undergraduate analytical chemistry course. Journal of Chemical Education, 89(9), 1128-1132. https://doi.org/10.1021/ed200685p

Kay, R., \& Kletskin, I. (2012). Evaluating the use of problem-based video podcasts to teach mathematics in higher education. Computers \& Education, 59(2), 619-627. https://doi.org/10.1016/j.compedu.2012.03.007

Kim, M. K., Kim, S. M., Khera, O. \& Getman, J. (2014). The experience of three flipped classrooms in an urban university: An exploration of design principles. The Internet and Higher Education, 22 (July), 37-50. https://doi.org/10.1016/j.iheduc.2014.04.003.

Lloyd, S. A. \& Robertson, C. L. (2012). Screencast tutorials enhance student learning of statistics. Teaching of Psychology, 39(1), 67-71. https://doi.org/10.1177/0098628311430640

Moravec, M., Williams, A., Aguilar-Roca, N., \& O'Dowd, D.K. (2010). Learn before lecture: A strategy that improves learning outcomes in a large introductory biology class. CBE-Life Sciences Education, 9(4), 473-481. https://doi.org/10.1187/cbe.10-04-0063

Ruddick, K. W. (2012). Improving chemical education from high school to college using a more hands-on approach (Unpublished doctoral dissertation). University of Memphis, Memphis, Tennessee.

Strayer, J. F. (2007). The effects of the classroom flip on the learning environment: A comparison of learning activity in a traditional classroom and a flip classroom that used an intelligent tutoring system 
(Unpublished doctoral dissertation). Ohio State University, Columbus, Ohio.

http://rave.ohiolink.edu/etdc/view?acc num=osu1189523914

Zappe, S., Leicht, R., Messner, J., Litzinger, T., \& Lee, H. (2009, June). "Flipping” the classroom to explore active learning in a large undergraduate course. Paper presented at the 2009 Annual Conference \& Exposition of the American Society for Engineering Education, Austin, Texas. Retrieved from https://peer.asee.org/4545

\section{APPENDIX}

\section{Student survey}

Free response questions:

1. What, specifically, do you see as the advantages of the flipped classroom?

2. What, specifically, do you see as the disadvantages of the flipped classroom?

3. Do you think the flipped classroom approach could be improved in this course? If so, how?

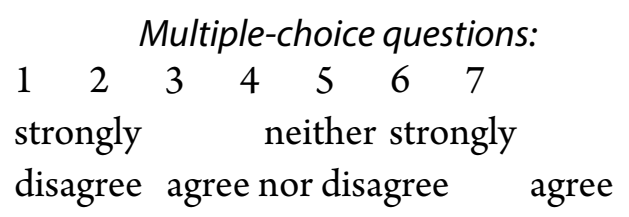

4. The video lectures helped me to understand the course material.

5. I liked watching the lessons on video.

6. The in-class activities that we did after watching the video lectures helped me to understand the course material.

7. The way the flipped topics were presented (i.e., watching a video lecture before class and then working on in-class activities during class time) really got me interested in those topics.

8. The way the flipped topics were presented (i.e., watching a video lecture before class and then working on in-class activities during class time) motivated me to learn more about those topics.

9. I feel as though I understood the material from the flipped class sections of the course better than the material from the traditional sections of the course.

10. I was more engaged with the flipped sections of the course than the traditional sections of the course.

11. I had more fun with the flipped sections of the course than the traditional sections of the course.

12. Working on hands-on activities in class is a better use of class time than listening to a traditional lecture.

13. I feel as though I learned more from the class time we spent on traditional lectures than from the class time we spent on activities.

\section{Yes/no questions \\ Yes No}

14. I watched all of the video assignments.

15. I would rather watch a traditional teacher-led lesson in class than a lesson video. 
Free response questions:

16. Please tell us WHY you preferred the video lectures to the in-class lectures.

17. Please tell us WHY you preferred the in-class lectures to the video lectures.

\title{
Demographics:
}

18. Please list ALL of your majors

19. Please list ALL of your minors

20. Please select your class year

Freshman Sophomore Junior Senior Other

21. Please indicate your gender

Male Female Other

22. Please provide your approximate GPA

23. Please indicate your age

End of Survey

\begin{abstract}
(c) (1)
Copyright for the content of articles published in Teaching \& Learning Inquiry resides with the authors, and copyright for the publication layout resides with the journal. These copyright holders have agreed that this article should be available on open access under a Creative Commons Attribution License 4.0 International (https://creativecommons.org/licenses/by/4.0). The only constraint on reproduction and distribution, and the only role for copyright in this domain, should be to give authors control over the integrity of their work and the right to be properly acknowledged and cited, and to cite Teaching \& Learning Inquiry as the original place of publication. Readers are free to share these materials-as long as appropriate credit is given, a link to the license is provided, and any changes are indicated.
\end{abstract}

